must not be originality or novelty in books, but the promotion of national welfare, of national safety, of national wealth and national solidarity. There must be no more battles of theory among you." $\mathrm{He}$ goes on to bid the teachers of law and economics show the way to German intellectual life by their good example. By a strange perversion of logic, policy dictated by political expediency is made the touchstone of truth and teaching, research and speculative thought are to be conditioned by predetermined conclusions, outside the terms of which they may not stray. The restrictions placed on the study of race and the history of culture are evidently now to be extended to jurisprudence and economics.

\section{Clinical Research at Guy's Hospital}

THE governors of Guy's Hospital and the governors of Guy's Hospital Medical School have accepted an invitation from the Medical Research Council to cooperate in the establishment of a new 'unit' for scientific research work in clinical medicine. It has been agreed that the Council will provide the salary of a whole-time director and of his assistants, with the cost of all apparatus and research material used by the unit. For its part, the Hospital will provide suitable laboratory accommodation free of charge, and will place and maintain beds at the disposal of the director : the latter is to be ex officio a member of the visiting staff, with a seat on the Medical Committee and the committees of the Medical School. These arrangements are to be effective for a period of five years in the first instance. Dr. Ronald $\mathrm{T}$. Grant, hitherto working in the service of the Council in the Department of Clinical Research at University College Hospital, London, has been appointed director of the new unit. The invitation was issued to Guy's Hospital by the Medical Research Council in accordance with its general policy of improving the facilities available in Great Britain for the scientific study of disease in the human subject, and with this end in view of increasing the number of higher appointments for whole-time workers in this field. The financial resources which the Council is able to apply to the purpose are those which were released when the senior post formerly maintained by the Council at University College Hospital, and held by Sir Thomas Lewis, received permanent endowment through the generous action of the Rockefeller Foundation.

\section{Electrical Launching Gear for Lifeboats on the Queen Mary}

THE electrical generators of the Queen Mary have a total capacity of about 10,000 kilowatts. There are in addition two 75 kilowatt generating sets driven by Parsons oil engines, which can be used for emergencies. Messrs. Samuel Taylor and Sons, Ltd., of Brierly Hill, Staffs, are supplying all the launching gear for the lifeboats. It includes twenty-four sets of gravity davits and winches. These davits run down inclined trackways carrying the boat with them until they finally reach their outboard position, when the boat is lowered from the davit head into the sea; the whole operation is done without stop- ping, the motive power being gravity. The cradle holding the boat is made in two portions, the carriage and the arm. The two portions run down the track bodily, after which the arm swings out of the carriage until the boat attains the outboard position and the lowering begins. There is no jerk anywhere, the motion being continuous. The movement of the davit is controlled by an electric winch mounted on a deck house. The winches are fitted with patent speed-sustaining brakes which limit the lowering speed of the lifeboats to one foot per second. For raising the lifeboats, after they have been lowered for any reason, such as lifeboat drill, the electric motors are used. Limit switches are provided which check the movement when the davits reach their inboard position and the interlocks make it impossible for the operator to make a mistake.

\section{Mining in Great Britain}

THE thirteenth annual report of the Secretary for Mines for the year 1933 from the Mines Department, which includes as usual the annual report of the Chief Inspector of Mines, has recently been issued (London : H.M. Stationery Office, 1934. 3s. 6d. net). The most important statement in this report is to be found in a review of the British coal-mining industry, which states that "Signs of an improvement in the position of the British coal-mining industry were evident in the latter part of 1933"'. This is a very satisfactory statement as showing that the coal production of the country is at last recovering from the serious slump that has affected it for so long. It must not, however, be supposed that all the difficulties have been overcome, because the report goes on to state that work at the pits was most irregular and that the prices of British coal were slightly lower than in the previous year. It is shown that various trade agreements made with different Governments of Europe have resulted upon the whole in an advantage to the coal trade of Great Britain. It is satisfactory to find that the utilisation of coal and the products derived from it are on the increase, and that serious attention is being given to the question of the use of com. pressed gas for motors. The statement, though now old, that during November 1933 the Secretary for Mines opened the first public filling station for vehicles using compressed gas, is repeated in the report, and it is decidedly interesting to have it thus authoritatively stated. It is obvious from the report that the mining of iron improved during 1933, the increase in the output being more marked in the second half of the year than in the first, as in the case of coal. The remainder of the report of the Secretary for Mines is not of great scientific importance, although his summary of the results obtained in the various testing stations is of a certain amount of public interest. The report of the Chief Inspector of Mines is, as usual, mainly of importance for the numerous tables which it presents.

\section{Weekly Weather Reports}

THE Weekly Weather Report of the Meteorological Office, Air Ministry, for the period February 28, 
1932-February 25, 1933, in the British Isles, is the fifth of a new series that began with vol. 45, published in 1929 ; the introduction to that volume explained the changes introduced in the new series. The week is commonly regarded as the unit of time best suited to the needs of agricultural meteorology, and this report is designed in other respects with the same needs in mind-for example, 'accumulated temperature', which is calculated with $42^{\circ} \mathrm{F}$. as base, above which many forms of plant begin to grow, and statistics of ground frosts, that is, frosts registered by a thermometer set on the grass and freely exposed to the sky as are the upper surfaces of the leaves of the topmost sprays of plants, are among the items included. The tables are set out in such a way that the whole year's succession of weekly data for a single station occupy one page. There are 57 stations, well distributed throughout the British Isles; these are also grouped into twelve so-called 'districts', and the deviations of the various meteorological elements, temperature, rainfall and sunshine, from normal values of these elements for a long period (generally 1881-1915) are averaged so as to give 'district values'. The district values are set out for individual weeks, and these are grouped into the four seasons, for each of which there is an appropriate seasonal mean deviation from normal. The season under review was one of generally deficient sunshine with more than the usual rainfall. The data for the Midlands and for the eastern districts of England and Scotland would be suitable in a study of the agricultural results of a wet spring, as that season was notably wet in those districts.

\section{Investigation of the West Kennet Avenue, Avebury}

Mr. Alexander Keirler has reported briefly in Antiquity of September on the results of an examination of the West Kennet Avenue, which leads from the Great Circle of Avebury to the Stone Circles on Overton Hill, undertaken recently with the view of determining its exact line. The Avenue has never been excavated scientifically; and in the spring of the present year operations were begun in a field about five hundred yards long near the middle of the course. Eight stones were still visible there, as well as one stone, which had never fallen, and one which had been re-erected by Mrs. Cunnington in 1912. The work began in April, and was planned to occupy three seasons. Fallen stones, or stones discovered beneath the surface, are being re-erected in the original holes as the work proceeds. Up to the time of writing, one buried stone, of which the previous existence had been unsuspected, and one fallen stone had been re-erected. In all, eight stone-holes have been discovered on the eastern side of the Avenue and eleven on the western side. One stone hole, despite careful searching, remains undiscovered. It is thought that the stone for which it is sought may not have penetrated the sub-soil, as the soil at the point where this stone most probably stood is unusually deep. Four other buried stones have been found and on three of these are markings which may be inscribed ornament. Post holes for timber uprights of which traces remain may, it is thought, represent a habitation site. The associated pottery is of the type known as Neolithic $B$, that is, Peterborough, which in this region belongs to the secondary occupation of the neighbouring Windmill Hill. Two finds of foreign stone, broken polished axes, are of augite-granophyre from Graig Llwyd. This occurs only at Penmaenmawr, North Wales, and previously only three specimens had been recorded outside Wales, one being from Windmill Hill, and equating with Neolithic $B$ pottery.

\section{Experimental Soil Science}

THE experimental study of the soil is so essential a branch of courses in agriculture, horticulture, botany and biology, that it seems a pity it is rather neglected, especially in the last two subjects, from elementary school courses up to courses in the universities. Most textbooks of botany, for example, devote little space to soil science in spite of the fact that the soil is the sole environment responsible for the physiological, biological and edaphic factors affecting one of the most important organs of the normal plant, namely, the root. We would therefore direct the attention especially of teachers of elementary biology and botany to an article on the experimental study of the soil by Dr. B. A. Keen, assistant director of Rothamsted Experimental Station, in School Nature Study, vol. 29, No. 117, October 1934. The author describes 18 experiments with a running commentary divided into four sections: what is meant by soil; organic matter; mineral matter; and separation of soil constituents. The paper is also published separately as Leaflet 22, copies of which can be obtained at $2 \frac{1}{2} d$. each, or $2 s$. a dozen, from Mr. E. G. Clarke, 7 Stanley Avenue, Wembley, Middlesex.

\section{Gulls Destroy Grasshoppers}

IT is surprisingly seldom that one comes across telling examples of the activity of birds as destroyers of harmful insects. F. Bradshaw records an interesting experience in Canada, on the west side of Last Mountain Lake, east of Liberty, Saskatchewan (Canadian Naturalist, 48, 68, April 1934). On June 18, 1933, he observed there what in the distance appeared to be a cloud of smoke, but on nearer approach turned out to be enormous flocks of the black-headed Franklin's gull. They alighted in column formation and gorged upon an army of grasshoppers. The number of birds present could not be estimated closely, but the column of close-set birds was a mile in extent and sixty birds in width, and two miles to the south-west an even larger cloud of gulls was seen. Estimates suggest that a Franklin's gull might devour 500 grasshoppers daily; the protective value of a flock, which at a very conservative estimate numbered more than a million, is, therefore, of considerable moment.

\section{Giuseppe Peano}

Among the eighteen papers in the Rendiconti del Seminario Mathematico e Fisico di Milano (7, 1933), the longest, and, to the general reader, most interesting, is an account of the scientific work of G. Peano of Turin (1858-1932). His publications, numbering 